\title{
Effects of using phenotypic means and genotypic values in GGE biplot analyses on genotype by environment studies on tropical maize (Zea mays)
}

\author{
I.S.C. Granato ${ }^{1}$, R. Fritsche-Neto ${ }^{1}$, M.D.V. Resende ${ }^{3}$ and F.F. Silva ${ }^{2}$ \\ 'Departamento de Genética, Escola Superior de Agricultura “Luiz de Queiroz", \\ Universidade de São Paulo, Piracicaba, SP, Brasil \\ ${ }^{2}$ Departamento de Zootecnia, Universidade Federal de Viçosa, Viçosa, \\ MG, Brasil \\ ${ }^{3}$ Departamento de Engenharia Florestal, Universidade Federal de Viçosa, \\ Viçosa, MG, Brasil \\ Corresponding author: I.S.C. Granato \\ E-mail: italo.granato@gmail.com \\ Genet. Mol. Res. 15 (4): gmr.15048747 \\ Received April 29, 2016 \\ Accepted July 26, 2016 \\ Published October 5, 2016 \\ DOI http://dx.doi.org/10.4238/gmr.15048747
}

Copyright $(2016$ The Authors. This is an open-access article distributed under the terms of the Creative Commons Attribution ShareAlike (CC BY-SA) 4.0 License.

\begin{abstract}
The objective of this study was to examine the effects of the type and intensity of nutritional stress, and of the statistical treatment of the data, on the genotype $\mathrm{x}$ environment ( $\mathrm{G} \times \mathrm{E}$ ) interaction for tropical maize (Zea mays). For this purpose, 39 hybrid combinations were evaluated under low- and high-nitrogen and -phosphorus availability. The plants were harvested at the V6 stage, and the shoot dry mass was estimated. The variance components and genetic values were assessed using the restricted maximum likelihood/best linear unbiased prediction method, and subsequently analyzed using the GGE biplot method. We observed differences in the performances of the hybrids depending on both the type and intensity of nutritional stress.
\end{abstract}


The results of relationship between environments depended on whether genotypic values or phenotypic means were used. The selection of tropical maize genotypes against nutritional stress should be performed for each nutrient availability level within each type of nutritional stress. The use of phenotypic means for this purpose provides greater reliability than do genotypic values for the analysis of the $\mathrm{G} x \mathrm{E}$ interaction using GGE biplot.

Key words: Maize; Nitrogen-use efficiency; Phosphorous-use efficiency; Mixed model; Principal component

\section{INTRODUCTION}

Nitrogen $(\mathrm{N})$ is maize (Zea mays) crops' most required nutrient. However, maize is grown in sub-optimal soil $\mathrm{N}$ availability conditions in several Brazilian regions. This nutrient limitation is mainly associated with the loss of $\mathrm{N}$ by volatilization, denitrification, and leaching (Gallais and Hirel, 2004), and an increase in N fertilizer supply has contributed to environmental pollution in many regions (Cui et al., 2009). Phosphorus (P) is another nutrient that has limited availability in some growing regions of Brazil, particularly those with acidic soils, and soil $\mathrm{P}$ reserves are non-renewable. This element is an integral component of various compounds, including phosphate sugars, phospholipids, enzymes related to energy metabolism, and DNA and RNA (Taiz and Zeiger, 2013). Reductions in leaf area and photosynthetic rates, and, therefore, biomass and grain production, result from plant deficiencies in N and P (Peng et al., 2013).

In this context, higher N- and P-use efficiencies (NUE and PUE) are fundamental, because they enable the sustainable production of satisfactory yields at a low cost (Fritsche-Neto and Borém, 2012). Moll et al. (1982) defined nutrient-use efficiency as the ratio of grain mass or shoot dry mass (SDM) per unit of available nutrient. Accordingly, several authors have observed genetic variability in grain yield under N- and P-limited conditions for maize (Parentoni and de Souza, 2008; Souza et al., 2008; Kant et al., 2011). However, the cultivars currently available have low nutrient-use efficiencies because they were developed in conditions of high nutrient availability, but the selection of cultivars that are adapted to stressful conditions is more effective if performed under limiting conditions (Presterl et al., 2003).

To avoid this problem, several breeding programs for nutritional stress have aimed to select superior genotypes for two or more stressors simultaneously. However, differing responses are expected from different genotypes when subjected to specific limiting conditions, i.e., to various stressors (Maia et al., 2011). This variability mainly results from the occurrence of a genotype $x$ environment ( $\mathrm{G}$ x E) interaction. Presterl et al. (2003) observed that the magnitude of the $\mathrm{G} \times \mathrm{E}$ interaction increases proportionally with the nutritional stress intensity. Therefore, large differences in genotype responses may occur because of the growth environment, even to the extreme of completely masking any genetic correlation among various environments. Consequently, genotypes must be evaluated under specific conditions of high and low $\mathrm{N}$ or P availability to maximize the effect of the $\mathrm{G} \times \mathrm{E}$ interaction.

Several methods have been proposed to examine the $\mathrm{G} x \mathrm{E}$ interaction. The differences among these methods lie in the concepts and biometric procedures used to estimate the effects and components of this interaction. Among them, multiplicative statistical models are very useful for evaluating the interaction in order to study genotype performance patterns in various

Genetics and Molecular Research 15 (4): gmr.15048747 
environments, and to make predictions concerning the mean performances of genotypes in specific environments. With this objective, Yan and Kang, (2002) described a method based on graphical analysis, termed the GGE biplot [main effects of genotypes $(\mathrm{G})$ and the G x E interaction], to evaluate adaptability and phenotypic stability. This graph is constructed by plotting the two principal components of a principal components analysis (PCA) using a sites regression model. According to Yan et al., (2007), GGE biplot analysis enables the identification of the performance patterns of various genotypes by elucidating the mean and genotype stability, and the relationships among environments. Furthermore, this analysis enables the identification of the environments that most contribute to the composition of the $\mathrm{Gx}$ E interaction.

The genotype effect may be considered fixed or random in biometric analyses, depending on the objective of the study. Genotypes are treated as fixed effects when the inference to be performed is restricted to the genotypes evaluated. Conversely, when the inference performed on the genotypes is extrapolated to the population, the genotype effect should be considered random, and its genetic values predicted using mixed-model equations.

Previous studies have suggested using mixed-model equations that are associated with biplot methods. Nuvunga et al. (2015) proposed the use of factor analysis (FA) together with mixed models for unbalanced data. Balestre et al. (2009) compared the use of genotypic values (random effects) with phenotypic means (fixed effects) for the study of the G $\mathrm{x} \mathrm{E}$ interaction using the restricted maximum likelihood/best linear unbiased prediction (REML/ BLUP) method. They reported that an increase in the accuracy of the GGE biplot occurs when genotypic values are used to perform the analysis. However, these authors failed to clarify the cause of this "superiority". Therefore, it is necessary to understand how the prediction and correction of genetic values for fixed effects using REML/BLUP affects the analysis of the G $x$ E interaction. Therefore, the main objective of this study was to evaluate the effect of the statistical treatment of the data, i.e., the use of genotypic values in GGE biplot to study the G $\mathrm{x} E$ interaction. In addition, we investigated the effects of the type and intensity of nutritional stress on tropical maize.

\section{MATERIAL AND METHODS}

\section{Experimental design}

To perform this study, 39 hybrid combinations were prepared using an interpopulational factorial scheme (unbalanced) by crossing 14 completely inbred lines that were derived from two sources of tropical maize germplasm. These inbred lines had been previously evaluated for their $\mathrm{N}$ - and P-use efficiency. The first source comprised seven lines that differed in terms of NUE (Group I), and the second source consisted of seven lines that differed in PUE (Group II). These crosses were performed reciprocally by mixing seeds of the same combination, thus disregarding the extra chromosomal inheritance.

The 39 resultant hybrid combinations were evaluated in two experiments. The first experiment evaluated two levels of $\mathrm{N}$ availability, high and low, and the second examined highand low-availability levels of P. A randomized-block design with two replicates, established in a factorial scheme (hybrid x N or P level), was implemented for these experiments. The experiments were conducted in a greenhouse $\left(20^{\circ} 45^{\prime} 14^{\prime \prime} \mathrm{S}, 42^{\circ} 52^{\prime} 53^{\prime \prime} \mathrm{W} ; 650 \mathrm{~m}\right.$ above mean se level) at Universidade Federal de Viçosa, Viçosa, Minas Gerais, Brazil during the October 2010 crop. The same environmental conditions were maintained throughout the growth period.

Genetics and Molecular Research 15 (4): gmr.15048747 
The experimental units consisted of $4-\mathrm{dm}^{3}(10 \mathrm{~cm}$ diameter $\mathrm{x} 50 \mathrm{~cm}$ height $)$ cylindrical polyvinyl chloride pots to which maize seedlings that had been pre-germinated in trays were transplanted 1 week after the emergence of seedlings. The substrate in the $\mathrm{N}$ experiment consisted of a mixture of sand washed with deionized water and vermiculite, at a 1:1 ratio, according to the method described by Walk et al., (2006). The substrate for the P experiment consisted of a mixture of $50 \%$ sand washed with deionized water, $37.5 \%$ vermiculite, and $12.5 \%$ soil (horizon "B" of dystrophic red-yellow latosol). The use of soil was necessary in order to adsorb $\mathrm{P}$ and prevent it from being readily available to the plants.

The solution used in the $\mathrm{N}$ experiment for both the low $\mathrm{N}(\mathrm{LN})$ and the high $\mathrm{N}(\mathrm{HN})$ levels is described by Chun et al. (2005). For the $\mathrm{HN}$ treatment, the nutrient solution was composed of $2.0 \mathrm{mM} \mathrm{Ca}\left(\mathrm{NO}_{3}\right)_{2}, 0.75 \mathrm{mM} \mathrm{K}_{2} \mathrm{SO}_{4}, 0.65 \mathrm{mM} \mathrm{MgSO}_{4}, 0.1 \mathrm{mM} \mathrm{KCl}, 0.25 \mathrm{mM}$ $\mathrm{KH}_{2} \mathrm{PO}_{4}, 1 \times 10^{-3} \mathrm{mM} \mathrm{H}_{3} \mathrm{BO}_{3}, 1 \times 10^{-3} \mathrm{mM} \mathrm{MnSO}_{4}, 1 \times 10^{-4} \mathrm{mM} \mathrm{CuSO}_{4}, 1 \times 10^{-3} \mathrm{mM} \mathrm{ZnSO}_{4}$, $5 \times 10^{-6} \mathrm{mM}\left(\mathrm{NH}_{4}\right)_{6} \mathrm{Mo}_{7} \mathrm{O}_{24}$, and $0.1 \mathrm{mM}$ Fe-EDTA. The LN solution contained $0.2 \mathrm{mM}$ $\mathrm{Ca}\left(\mathrm{NO}_{3}\right)_{2}$, which was 10 -fold less than in the $\mathrm{HN}$ solution, and $\mathrm{Ca}^{2+}$ was compensated for by supplementation with $\mathrm{CaCl}_{2}$. In the second experiment, $\mathrm{P}$ was supplemented in the form of triple superphosphate. For the low-P availability level (LP), $6.12 \mathrm{mmol} / \mathrm{dm}^{3}$ of $\mathrm{P}$ was mixed with the substrate, while the high-P availability level (HP) received $34.56 \mathrm{mmol} / \mathrm{dm}^{3}$. The other nutrients were supplied via a nutrient solution as described by Passos (1996) without any addition of $\mathrm{P}$, which contained $1.0 \mathrm{M} \mathrm{Ca}\left(\mathrm{NO}_{3}\right)_{2} \cdot 4 \mathrm{H}_{2} \mathrm{O}, 1.0 \mathrm{M} \mathrm{MgSO}_{4} \cdot 7 \mathrm{H}_{2} \mathrm{O}, 0.5 \mathrm{M} \mathrm{K}_{2} \mathrm{SO}_{4}$, $0.32 \mathrm{mM} \mathrm{CuSO}_{4} \cdot 5 \mathrm{H}_{2} \mathrm{O}, 46.0 \mathrm{mM} \mathrm{H} \mathrm{BO}_{3}, 0.073 \mathrm{mM}\left(\mathrm{NH}_{4}\right)_{6} \mathrm{Mo}_{7} \mathrm{O}_{24}, 9.1 \mathrm{mM} \mathrm{MnCl} \cdot 4 \mathrm{H}_{2} \mathrm{O}$, $0.76 \mathrm{mM} \mathrm{ZnSO}_{4} \cdot 7 \mathrm{H}_{2} \mathrm{O}$, and $38.0 \mathrm{mM} \mathrm{Fe}$-EDTA. A $250-\mathrm{mL}$ aliquot of the nutrient solution was supplied every 2 days, starting on the 7 th day after seedling emergence.

The plants were harvested at the vegetative stage of six-fully expanded leaves (V6), which was approximately 25 days after sowing. Plant shoots were separated from the root system, stored in paper bags, and dried in a forced-air oven at $60^{\circ} \mathrm{C}$ for $72 \mathrm{~h}$. The SDM of each plant was obtained from these samples.

\section{Genetic and statistical analyses}

To calculate the variance components and the genotypic values of the hybrid combinations for each availability level of N or P, the SDM data were analyzed using the REML/ BLUP method, as described by Resende (2002), considering the following global model:

$$
y=X r+T a+W n+Z g+V i+e
$$

where $y$ is the vector of phenotypic values of the hybrids; $r$ is the vector of the replicate effects (assumed to be fixed) added to the general mean; $a$ is the vector of the nutrient type effects (assumed to be fixed); $n$ is the vector of the nutrient availability level within each type of nutrient (assumed to be fixed); $g$ is the vector of the genotypic effects of the hybrids (assumed to be random); $i$ is the vector of the effects of the interaction between the hybrid and nutrient availability level for a given nutrient (assumed to be random); $e$ is the vector of random errors; and $X, T, W, Z$, and $V$ are the incidence matrices relating the effects of $r, a, n$, $g$, and $i$, respectively, to vector $y$.

Based on the above model, reduced models for the individual analysis of each availability level of $\mathrm{N}$ or $\mathrm{P}$, and for a combined analysis that considered the levels of both $\mathrm{N}$ and $\mathrm{P}$ were analyzed.

Genetics and Molecular Research 15 (4): gmr.15048747 
To solve the mixed-model equations, the variance components were assumed to be unknown, and were estimated using the REML method in the Computerized Genetic Selection (SELEGEN)-REML/BLUP (Resende, 2007) and the Statistical Analysis Software (SAS) 9.3 (SAS Institute Inc., 2013) computational statistical packages. The model effects were assessed using the likelihood ratio test (Sturion and Resende, 2010).

\section{Analysis of the $\mathbf{G} \times \mathbf{E}$ interaction}

A decomposition of the $\mathrm{G} x \mathrm{E}$ interaction into its simple and complex components was performed using the method described by Vencovsky and Barriga, (1992):

$$
\sigma_{g e}^{2}=(1 / 4) \cdot\left(\hat{\sigma}_{g 1}-\hat{\sigma}_{g 2}\right)^{2}+(1 / 2) \cdot\left(1-r_{g 12}\right) \cdot \hat{\sigma}_{g 1} \cdot \hat{\sigma}_{g 2}
$$

Where $\sigma_{g a}^{2}$ is the variance component of the genotype x environment interaction; $\hat{\sigma}_{g 1}$ and $\hat{\sigma}_{g 2}$ are the genetic standard deviations for environments 1 and 2, respectively; and $r_{g 12}$ is the correlation between the adjusted means of the hybrids in environments 1 and 2 . The two parts of the right-hand side of this equation, before and after the addition symbol, refer to the simple and complex components of the G $\mathrm{x}$ E interaction, respectively.

Two types of data were used to perform the GGE biplot analyses. One analysis evaluated the phenotypic means of the hybrid combinations for SDM (genotype effect assumed to be fixed) using the following model:

$$
\bar{Y}_{i j}-\mu=G_{i}+E_{j}+G E_{i j}
$$

where $\bar{Y}_{i j}$ represents the phenotypic mean of hybrid i in environment $\mathrm{j}$ (HN or LN; HP or LP); $\mu$ is the global mean; $E_{j}$ is the effect of environment $j$; $G_{i}$ is the effect of hybrid $i$; and $G_{i j}$ is the effect of the interaction between hybrid $i$ and environment $j$.

The second type of data used in the GGE biplot analysis was the genotypic values of the hybrid combinations (genotype effect assumed to be random):

$$
\bar{Y}_{i j}-\mu-E_{j}=G_{i}+G E_{i j}
$$

where $\bar{Y}_{i j}$ represents the genotypic value of hybrid i in environment $\mathrm{j}$ (HN or LN; HP or LP); $\mu$ is the global mean; $E_{j}$ is the effect of environment $j$; $G_{i}$ is the effect of hybrid $i$; and $G_{i j}$ is the effect of the interaction between hybrid $i$ and environment $j$.

\section{GGE biplot analysis}

The GGE biplot model does not separate the genotype effect from the effect of the $\mathrm{G} \times \mathrm{E}$ interaction, and combines them in two multiplicative terms, which can be found in the following equation:

$$
Y_{i j}-\mu-\beta_{j}=g_{i 1} e_{1 j}+g_{i 2} e_{2 j}+\varepsilon_{i j}
$$

Genetics and Molecular Research 15 (4): gmr.15048747 
where $Y_{i j}$ is the performance expected from hybrid $i$ in environment $j ; \mu$ is the global mean of the observations; $\beta_{j}$ is the main effect of environment $j ; g_{i 1}$ and $e_{1 j}$ are the main scores for the ith hybrid in the jth environment, respectively; $g_{\mathrm{i} 2}$ and $\mathrm{e}_{2 \mathrm{j}}$ are the secondary scores for the ith hybrid in the jth environment, respectively; and $\varepsilon_{\mathrm{ij}}$ is the residual not explained by the combined effects. Therefore, the construction of the biplot in the GGE model occurs through a simple scatter plotting of $g_{i 1}$ and $g_{i 2}$ for the genotypes and $e_{1 j}$ and $e_{2 j}$ for environments 1 and 2 using singular value decomposition, as follows:

$$
Y_{i j}-\mu-\beta_{j}=\lambda_{1} \xi_{i 1} \eta_{1 j}+\lambda_{2} \xi_{i 2} \eta_{2 j}+\varepsilon_{i j}
$$

where $\lambda_{1}$ and $\lambda_{2}$ are the largest eigenvalues of the first and second principal components (PCA and $\mathrm{PCA}_{2}$ ), respectively; $\xi_{\mathrm{i} 1}$ and $\xi_{\mathrm{i} 2}$ are the eigenvectors of the ith hybrid for $\mathrm{PCA}_{1}$ and $\mathrm{PCA}_{2}$, respectively; and $\eta_{1 \mathrm{j}}$ and $\eta_{2 \mathrm{j}}$ are the eigenvectors of the jth environment for $\mathrm{PCA}_{1}$ and $\mathrm{PCA}_{2}$, respectively. All of the GGE biplot analyses were performed using the GGE biplot analysis software (Yan, 2001).

\section{RESULTS}

A significant effect of hybrid was observed on SDM in the individual deviance analysis for each availability level of $\mathrm{P}$ (P experiment) or $\mathrm{N}$ (N experiment; Table 1). The coefficients of experimental variation were within the acceptable limits for abiotic stress studies (Souza et al., 2008; Fritsche-Neto et al., 2010). The mean SDM of the hybrids decreased by approximately $54 \%$ under LP compared to HP, and by approximately $51 \%$ under LN compared to HN. The heritabilities had medium-to-low magnitudes in the $\mathrm{N}$ experiment and medium-to-high magnitudes in the P experiment. A decrease in the magnitude of heritability by approximately $48 \%$ was observed for SDM at low P availability and by approximately $30 \%$ at LN availability in relation to the conditions of high availability of those nutrients.

Table 1. Likelihood ratio test values of the hybrid effect according to an analysis of individual deviance (under high or low availability of $\mathrm{N}$ or P), broad-sense heritability estimates $\left(h^{2}\right)$, and the means and coefficients of experimental variation $(\mathrm{CV} \%)$ for shoot dry mass of 39 maize hybrid combinations.

\begin{tabular}{l|c|c|c|c}
\hline \multirow{2}{*}{ Effects } & \multicolumn{2}{|c|}{ Phosphorus (P) } & \multicolumn{2}{c}{ Nitrogen (N) } \\
\cline { 2 - 5 } & Low & High & Low & High \\
\hline Hybrid & $4.06^{* *}$ & $19.1^{* * *}$ & $3.65^{*}$ & $0.69^{* * *}$ \\
\hline$h^{2}$ & 0.32 & 0.66 & 0.30 & 0.43 \\
\hline Mean & 1.10 & 2.42 & 0.45 & 0.93 \\
\hline CV $(\%)$ & 28.51 & 19.77 & 19.59 & 21.96 \\
\hline
\end{tabular}

$* * * \mathrm{P}=0.01,{ }^{* *} \mathrm{P}=0.05, * \mathrm{P}=0.10$.

Considering the combined results of the analyses for each nutrient (Table 2) and the global analysis for both types of nutrients and both levels within each nutrient (Table 3), a significant effect was observed of hybrid, nutrient, and availability level within each nutrient, and the hybrid $\mathrm{x}$ environment interaction within each nutrient. A decomposition of the components of the hybrid $x$ nutrient level interaction (Table 3) demonstrated that the amount of variation explained by the complex part of the interaction was medium-to-high, with magnitudes of $51.66 \%$ in the $\mathrm{N}$ experiment and $35.23 \%$ in the P experiment.

Genetics and Molecular Research 15 (4): gmr.15048747 
Table 2. Likelihood ratio test values of the hybrid and hybrid $x$ nutrient level interaction effects (under conditions of high or low availability of $\mathrm{N}$ or P), percent estimate of the complex part (B) of the G $\mathrm{x}$ E interaction, and the means and coefficients of experimental variation (CV\%) for shoot dry mass of 39 maize hybrid combinations.

\begin{tabular}{l|c|c}
\hline Effects & $\mathrm{P}$ & $\mathrm{N}$ \\
\hline Hybrid & $7.61^{* * *}$ & $8.56^{* * *}$ \\
\hline Hybrid x nutrient level & $29.77^{* * *}$ & $14.08^{* * *}$ \\
\hline B (\%) & 35.23 & 50.66 \\
\hline Mean & 1.76 & 0.69 \\
\hline CV $(\%)$ & 23.08 & 22.78 \\
\hline
\end{tabular}

$* * * \mathrm{P}=0.01, * * \mathrm{P}=0.05, * \mathrm{P}=0.10$.

Table 3. F-test and likelihood ratio test (LRT) values for a combined analysis of the effects of nutrient, nutrient availability levels, hybrid, and the hybrid x nutrient availability level interaction, and estimates of the means and coefficients of experimental variation (CV\%) for shoot dry mass of 39 maize hybrid combinations exposed to two $\mathrm{N}$ and $\mathrm{P}$ availability conditions (high and low).

\begin{tabular}{l|c}
\hline Effects & F \\
\hline Fixed $^{\dagger}$ & $890.01^{* * *}$ \\
\hline Nutrient & $389.63^{* * *}$ \\
\hline Level/Nutrient & LRT \\
\hline Random ${ }^{\dagger \dagger}$ & $4864.60^{* * *}$ \\
\hline Hybrid & $4675.30^{* * *}$ \\
\hline Hybrid x Level/Nutrient & 1.23 \\
\hline Mean & 25.54 \\
\hline CV $(\%)$ & 23 \\
\hline
\end{tabular}

†alues obtained using the F-test; ${ }^{\dagger}$ Values obtained using the likelihood ratio test; $* * * \mathrm{P}=0.01, * * \mathrm{P}=0.05, * \mathrm{P}=$ 0.10 .

In the biplot analysis for the discrimination and representation of environments within each nutritional stressor (N or P; Figure 1A, B, D, and E), the first principal component, at both HN and low LN availability and HP and LP availability, explained very close to or greater than $80 \%$ of the total variation. All of the variation (100\%) was explained by the two principal components, because there were only two environments analyzed for each nutrient. Considering the global combined graphical analysis, i.e., simultaneously analyzing the two nutrient availability levels within each nutrient (HN, LN, HP, and LP) for which there were four principal components, the first two principal components explained 82.2 and $93.3 \%$, of the variation in yield with genotypic and phenotypic values, respectively (Figure 1C and F).

In the visual representation of the $\mathrm{G} \times \mathrm{E}$ interaction in the GGE biplot, the angles formed between the vectors of each environment are related to the correlation between them (Yan and Tinker, 2006). Therefore, it was observed that the relationship between environments differed when using genotypic values compared to when using phenotypic means in the analysis of the $\mathrm{G} \times \mathrm{E}$ interaction. The correlation was stronger when using genotypic values for both the N (Figure 1A and D) and P (Figure 1B and E) results. Furthermore, in the global combined analysis (by GGE biplot), two groups of environments were formed when using genotypic values. One group was formed by the HN and LN levels and another by the HP and LP levels (Figure 1C). Conversely, three groups were formed when the phenotypic means were used (Figure 1F). The high availability levels of both nutrients remained together, forming one mega-environment group (HN and HP). The other two environments, LN and LP, formed distinct groups. 

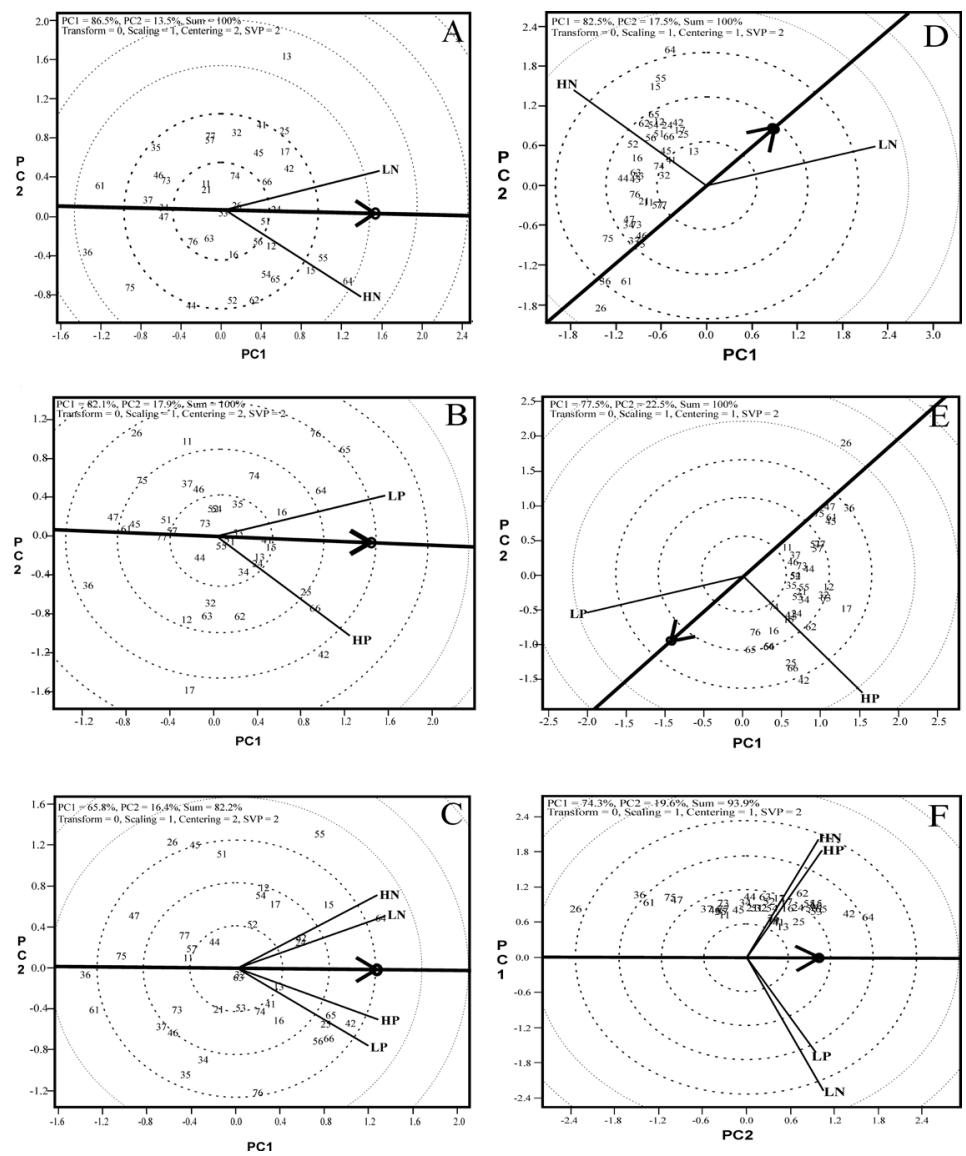

Figure 1. Discrimination and representativeness of the high and low nitrogen availability (HN and LN, respectively) and high and low phosphorus availability (HP and LP, respectively) environments and of these four environments simultaneously for shoot dry mass, using genotypic values $(\mathbf{A}, \mathbf{B}, \mathbf{C})$ and phenotypic means at the environmental level (D, E, F).

When analyzing the discrimination between hybrids using the GGE biplot method, the vector length is proportional to the standard deviation of each environment. Therefore, in the global combined analysis using both the phenotypic means (Figure 1F) and the genotypic values (Figure 1C), the stress environments indicated the highest capacity for discrimination among genotypes under optimal growth conditions.

\section{DISCUSSION}

The significance of the hybrid effect indicates that there was genetic variability in SDM among the genotypes evaluated, which enables the selection for genetic gains for each level of N and P (Chun et al., 2005; Fritsche-Neto et al., 2010). The coefficients of experimental variation were within the acceptable limits for studies of abiotic stress (Souza et al., 2008; Fritsche-Neto et al., 2010), indicating good accuracy of the results obtained. 
The magnitude of genetic variance usually varies with the stress level. Accordingly, Coque and Gallais, (2006) reported that, in general, there is a decrease in genetic variability and heritability under stressful conditions, which may complicate the selection of phenotypes. However, significant genetic variability was still evident in the results, despite this marked reduction in genetic variability and heritability. This indicates that stress was effective, because a significant decrease in the mean genetic variability and heritability of hybrids was observed for SDM, although performance did still differ among individuals under nutritional stress.

The GGE biplot explained a large proportion of the sum of squares of the $\mathrm{G} \times \mathrm{E}$ interaction, which indicates that the results were reliable. The clustering pattern formed for different $\mathrm{N}$ and $\mathrm{P}$ stress levels in the present study was similar to that reported by Betrán et al. (2003), who observed that environments of high and low nutritional availability failed to cluster (Figure 1). These results enable us to infer that there were differences in the performances of the hybrids that depended upon both the type and intensity of nutritional stress.

The different performances by the hybrids under both types of stress and high and low nutrient availability levels may have been related to differences in gene expression in the highand low-availability environments. Therefore, the selection of superior genotypes (in terms of genetic gains) regarding NUE and PUE simultaneously is difficult. The selection of tropical maize hybrids for specific environments, i.e., for each level of nutritional availability within each type of nutrient stress, is indicated (Souza et al., 2008) to positively maximize the G x E interaction (Presterl et al., 2003).

There were significant differences in the correlation between environments, which was estimated by the following equation:

$$
r_{g}=\frac{\hat{\sigma}_{g}^{2}-\hat{\sigma}_{g e}^{2}}{\sqrt{\hat{\sigma}_{g 1}^{2} \cdot \hat{\sigma}_{g 2}^{2}}}
$$

There were also significant differences in the clustering patterns between analyses using genotypic values and those using phenotypic means. The strongest correlation between the stress and stress-free environments was observed when using genotypic values, both for the $\mathrm{N}$ (Figure 1A and $\mathrm{D}$ ) and $\mathrm{P}$ (Figure $1 \mathrm{~B}$ and $\mathrm{E}$ ) experiments. This finding may result from the statistical treatment of the data. There is a double penalty for random effects (shrinkage effect) when using genotypic values; the first is associated with mixed-model equations, and the second with the decomposition of the singular values in the GGE biplot analysis. Furthermore, there is a double decomposition of the phenotypic values into their genotypic, environmental, and interaction components $(F=G+E+G E)$, which ultimately underestimates the magnitude of the $\mathrm{G} x$ E interaction component, thereby increasing the magnitude of the correlation between contrasting environments.

Conversely, when the phenotypic means of the hybrids were used in the GGE biplot analysis, the clustering pattern formed for the types and levels of nutritional stress was as expected. This pattern occurred because the $\mathrm{HN}$ and HP availability treatments theoretically represented the same environment. Therefore, in the present study, the use of phenotypic means was the best choice for the statistical treatment of data to be used in GGE biplot analyses, in contrast to the findings by Balestre et al. (2009).

Nuvunga et al. (2015) also used mixed models that were associated with FA for

Genetics and Molecular Research 15 (4): gmr.15048747 
genotype by environment studies. According to the authors, the FA model is robust, particularly in its ability to deal with highly unbalanced data. However, when using that method, the authors overparameterized the model, including covariance structures. In addition, FA models are difficult to implement and increase computational demand, and can lead to convergence problems. Moreover, the biplot graphs generated by the FA model were similar to those created with a GGE biplot model using phenotypic means with balanced data. Therefore, model choice should be balanced between accuracy and complexity. In this context, the use of phenotypic means to conduct GGE biplots results in a greater understanding of $\mathrm{G} \times \mathrm{E}$ and is easily implemented.

Low levels of nutritional availability provided the greatest capacity for genotype discrimination under both types of stress, which is similar to that reported by Worku et al. (2007). Therefore, genotype evaluations should be performed under stressful conditions that will lead to a better assessment of genetic variability, and, therefore, greater selection gains. Thus, the selection of tropical maize genotypes against nutritional stress should be performed for each nutrient availability level within each type of nutritional stress. For this purpose, the use of phenotypic means is more reliable than genotypic values for assessing the $\mathrm{G} \times \mathrm{E}$ interaction using GGE biplot analysis.

\section{Conflicts of interest}

The authors declare no conflict of interest.

\section{ACKNOWLEDGMENTS}

We thank Coordenação de Aperfeiçoamento de Pessoal de Nivel Superior (CAPES) program for granting a scholarship, and Fundação de Amparo à Pesquisa do Estado de Minas Gerais (FAPEMIG) for funding research projects \#CAG-APQ-00559-12 and \#CAGAPQ-00555-12.

\section{REFERENCES}

Balestre M, Von Pinho RG, Souza JC and Oliveira RL (2009). Genotypic stability and adaptability in tropical maize based on AMMI and GGE biplot analysis. Genet. Mol. Res. 8: 1311-1322. http://dx.doi.org/10.4238/vol8-4gmr658

Betrán FJ, Beck D, Bänziger M and Edmeades GO (2003). Genetic analysis of inbred and hybrid grain yield under stress and nonstress environments in tropical maize. Crop Sci. 43: 807-817. http://dx.doi.org/10.2135/cropsci2003.8070

Chun L, Mi G, Li J, Chen F, et al. (2005). Genetic analysis of maize root characteristics in response to low nitrogen stress. Plant Soil 276: 369-382. http://dx.doi.org/10.1007/s11104-005-5876-2

Coque $\mathrm{M}$ and Gallais A (2006). Genomic regions involved in response to grain yield selection at high and low nitrogen fertilization in maize. Theor. Appl. Genet. 112: 1205-1220. http://dx.doi.org/10.1007/s00122-006-0222-5

Cui Z, Zhang F, Mi G, Chen F, et al. (2009). Interaction between genotypic difference and nitrogen management strategy in determining nitrogen use efficiency of summer maize. Plant Soil 317: 267-276. http://dx.doi.org/10.1007/s11104-008-9807-x

Fritsche-Neto R and Borém A (2012). Plant breeding for abiotic stress tolerance. Springer, Heidelberg.

Fritsche-Neto R, Miranda GV, De Lima RO, Souza LVd, et al. (2010). Herança de caracteres associados à eficiência de utilização do fósforo em milho. Pesq. Agropec. Bras. 45: 465-471. http://dx.doi.org/10.1590/S0100204X2010000500005

Gallais A and Hirel B (2004). An approach to the genetics of nitrogen use efficiency in maize. J. Exp. Bot. 55: 295-306. http://dx.doi.org/10.1093/jxb/erh006

Kant S, Bi YM and Rothstein SJ (2011). Understanding plant response to nitrogen limitation for the improvement of crop nitrogen use efficiency. J. Exp. Bot. 62: 1499-1509. http://dx.doi.org/10.1093/jxb/erq297

Genetics and Molecular Research 15 (4): gmr.15048747 
Maia C, DoVale JC, Fritsche-Neto R, Cavatte PC, et al. (2011). The difference between breeding for nutrient use efficiency and for nutrient stress tolerance. Crop Breed. Appl. Biotechnol. 11: 270-275. http://dx.doi.org/10.1590/ $\underline{\text { S1984-70332011000300010 }}$

Moll RH, Kamprath EJ and Jackson WA (1982). Analysis and interpretation of factors which contribute to efficiency of nitrogen utilization. Agron. J. 74: 562-564. http://dx.doi.org/10.2134/agronj1982.00021962007400030037x

Nuvunga JJ, Oliveira LA, Pamplona AKA, Silva CP, et al. (2015). Factor analysis using mixed models of multi-environment trials with different levels of unbalancing. Genet. Mol. Res. 14: 14262-14278. http://dx.doi.org/10.4238/2015. November.13.10

Parentoni SN and de Souza CL (2008). Phosphorus acquisition and internal utilization efficiency in tropical maize genotypes. Pesq. Agropec. Bras. 43: 893-901. http://dx.doi.org/10.1590/S0100-204X2008000700014

Passos LP (1996). Métodos analíticos e laboratoriais em fisiologia vegetal. EMBRAPA/CNPGL, 223.

Peng Y, Yu P, Li X and Li C (2013). Determination of the critical soil mineral nitrogen concentration for maximizing maize grain yield. Plant Soil 372: 41-51. http://dx.doi.org/10.1007/s11104-013-1678-0

Presterl T, Seitz G, Landbeck M, Thiemt EM, et al. (2003). Improving nitrogen-use efficiency in European maize: Estimation of quantitative genetic parameters. Crop Sci. 43: 1259-1265. http://dx.doi.org/10.2135/cropsci2003.1259

Resende MDV (2002). Genética biométrica e estatística no melhoramento de plantas perenes. Embrapa Florestas, Colombo.

Resende MDV (2007). SELEGEN-REML/BLUP: sistema estatístico e seleção genética computadorizada via modelos lineares mistos. Embrapa Florestas.

SAS Institute Inc (2013). SAS/STAT 13.1 User's Guide. SAS Institute Inc., Cary.

Souza LVD, Miranda GV, Galvão JCC, Eckert FR, et al. (2008). Genetic control of grain yield and nitrogen use efficiency in tropical maize. Pesq. Agropec. Bras. 43: 1517-1523. http://dx.doi.org/10.1590/S0100-204X2008001100010

Sturion JA and Resende MDV (2010). Avaliação genética e análise de deviance em um teste desbalanceado de procedência e progênie de Ilex paraguariensis. Pesq. Flor. Bras 30: 157-160. http://dx.doi.org/10.4336/2010.pfb.30.62.157

Taiz LT and Zeiger E (2013). Fisiologia vegetal, 5th edn. Artmed, Porto Alegre.

Vencovsky R and Barriga P (1992). Genética biométrica no fitomelhoramento. Sociedade Brasileira de Genética, Ribeirão Preto.

Walk TC, Jaramillo R and Lynch JP (2006). Architectural tradeoffs between adventitious and basal roots for phosphorus acquisition. Plant Soil 279: 347-366. http://dx.doi.org/10.1007/s11104-005-0389-6

Worku M, Bänziger M, Erley GS, Friesen D, et al. (2007). Nitrogen uptake and utilization in contrasting nitrogen efficient tropical maize hybrids. Crop Sci. 47: 519-528. http://dx.doi.org/10.2135/cropsci2005.05.0070

Yan W (2001). GGEbiplot- A windows application for graphical analysis of multienvironment trial data and other types of two-way data. Agron. J. 93: 1111-1118. http://dx.doi.org/10.2134/agronj2001.9351111x

Yan W and Kang MS (2002). GGE biplot analysis: a graphical tool for breeders, geneticists, and agronomists. 1st edn, CRC Press, Boca Raton.

Yan W and Tinker NA (2006). Biplot analysis of multi-environment trial data: Principles and applications. Can. J. Plant Sci. 86: 623-645. http://dx.doi.org/10.4141/P05-169

Yan W, Kang MS, Ma B, Woods S, et al. (2007). GGE biplot vs. AMMI analysis of genotype-by-environment data. Crop Sci. 47: 643-653. http://dx.doi.org/10.2135/cropsci2006.06.0374

Genetics and Molecular Research 15 (4): gmr.15048747 